\title{
Application of inverse methodology to estimation of chloride diffusion coefficient in concrete of prestressed precast slab
}

\author{
Zofia Szweda ${ }^{1, *}$, and Zbigniew Buliński ${ }^{2}$ \\ ${ }^{1}$ Department of Building Structures, Faculty of Civil Engineering - Structure, SUT, Gliwice, Poland \\ ${ }^{2}$ Institute of Thermal Technology, Faculty of Energy and Environmental Engineering, SUT, Poland
}

\begin{abstract}
Work presents an investigation of chloride penetration of HC500 prestressed concrete slabs made of precast concrete. This type of concrete slabs is widely used to construct floors in steel or reinforced concrete framing buildings. In such solutions ceiling can be considered as a simple-supported beam. Considered precast concrete was made of C50/C60 concrete with use of Portland cement CEM II 52.5 R. Investigated specimens were sampled directly from the upper part of prestressed concrete slabs. The process of chloride penetration in concrete can be described by the nonlinear diffusion equation. In the paper Bayesian inverse technique was applied to estimate diffusion coefficient of chloride in concrete treated as a saturated porous material. Unknown distribution of estimated parameters was sampled with use of Metropolis-Hastings algorithm which allowed us to obtain unknown values and their error bounds. Obtained values of diffusion coefficient were confronted against values obtained with use of norms: NT BUILD 443 and ASTM C $1556-03$ and against previously developed methodology based on the analytical solution of the diffusion equation.
\end{abstract}

\section{Introduction}

Large span ceilings applicable in single-space interiors with various functions (storage buildings, industrial and commercial) are often made of pre-fabricated pre-stressed concrete slabs (fig. 1). The use of such ceilings allows very fast assembly of the structure without the need for formwork and supports preventing the effects of creep. This gives big economic benefits and allows to become independent from climatic conditions [1]. Considered plates HC-500 are prefabricated, pre-stressed concrete elements for use in the building skeleton of reinforced concrete or steel, working as simply supported beams with a maximum span of 21 $\mathrm{m}$ [2]. These plates are made of concrete C50/60 with coefficient $\mathrm{w} / \mathrm{c}=0.31$ with use of Portland cement CEM II 52,5 R. These plates may be used in the environmental conditions corresponding to the classes of exposure: $\mathrm{X} 0, \mathrm{XC1}, \mathrm{XC} 2 \mathrm{i} \mathrm{XC} 3$ (according to the standards: PN-EN 1992-1-1:2004 [3], PN-EN 206-1: 2003 [4]).

\footnotetext{
${ }^{*}$ Corresponding author: zofia.szweda@polsl.pl
} 
The critical concentration of chloride ions permitted in compressed structures for safety reasons varies depending on the standard considered. In the Polish standard PN-EN 1992-11:2004 the critical concentration equals to $C_{K}=0,1$ or $0.2 \%$ cement based weight [3]. The British standard BS 8110: Part 1: 1997 is less restrictive and it allows the critical chloride concentration from 0.1 up to $0.4 \%$ cement content. The most restrictive is the Eropean standard ACI 318M-02/318RM02, which allows chloride concentration on the level less than $0,06 \%$ cement weight $[6,7]$.
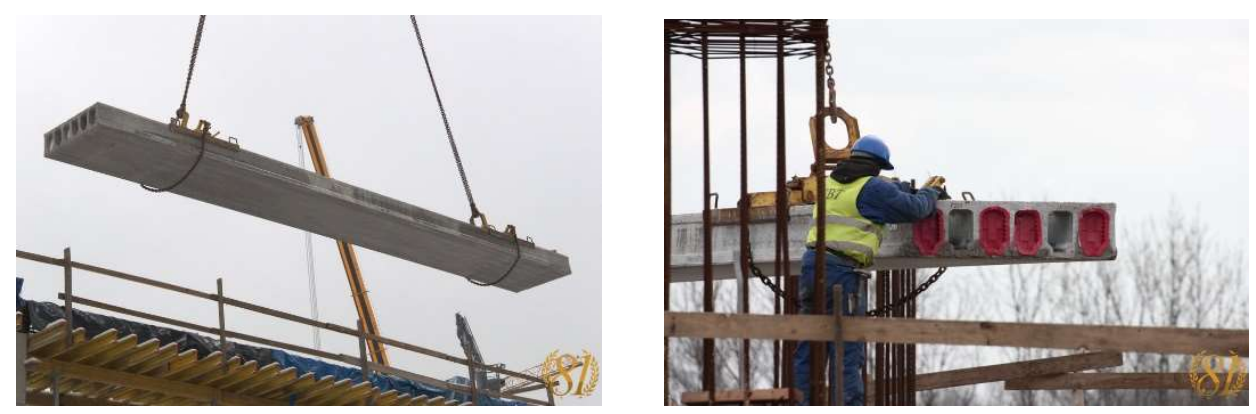

Fig. 1. Mounting the hollow core slabs [11].

The rate of penetration of chloride ions into wet concrete is described by diffusion coefficients. Therefore, a very important issue, especially in the case of pre-stressed concrete structures, is determination of the value of this coefficient.

The aim of the work was to compare different methods of determining the value of migration coefficient and diffusion of chlorides of concrete taken directly from prefabricated pre-stressed concrete slabs HC-500. Bayesian inverse technique will be applied to estimate diffusion and migration coefficients of chloride in concrete treated as a saturated porous material. In the proposed work, the unknown distribution of estimated parameters was sampled with use of Metropolis-Hastings algorithm which allowed us to obtain unknown values and their error bounds. Obtained values of diffusion coefficient was confronted against values obtained with use of norms: NT BUILD 443 [8] and ASTM C 1556-03 [9] and against previously developed methodology based on the analytical solution of the migration equation [10].

\section{Determination of diffusion coefficients with use of analytical solutions of the diffusion and migration equations}

Investigated specimens were sampled directly from the upper part of pre-stressed concrete slabs using a diamond core drilling machine with diameter $8 \mathrm{~cm}$. Considered precast concrete with $\mathrm{w} / \mathrm{c}=0.32$ and average compressive strength of concrete $\mathrm{f}_{\mathrm{ctm}}=65 \mathrm{MPa}$ was made of C50/C60 concrete with use of Portland cement CEM II $52.5 \mathrm{R}: 550 \mathrm{~kg} / \mathrm{m}^{3}$ and Crushed BASALT: $1304 \mathrm{~kg} / \mathrm{m}^{3}$ [2].

Six cylindrical samples having $80 \mathrm{~mm}$ in diameter and $50 \mathrm{~mm}$ in high were tested, the specimen side surfaces were covered with resin to ensure unidirectional chloride ions flow. Cylinders containing 3\% $\mathrm{NaCl}$ solution were tightly attached to the upper surface of the cylindrical concrete samples and cathodes made of stainless steel were placed inside and adjusted to the cross-section of the cylindrical elements. Three samples connected in parallel in an electric circuit were simultaneously tested on a damp sponge, under which there was a platinum-coated anode made of titanium (rys. 2b, c). After saturating the samples with distilled water for three days, the system was connected to a DC voltage source $\mathrm{U}=18 \mathrm{~V}$. 
Chloride migration studies were measured at two time instances $t_{1}=24$ and $t_{2}=48$ hours. The $\mathrm{NaCl}$ solution was replaced after 24 hours. Throughout the study period, the temperature of the solutions was constant and was around $20^{\circ} \mathrm{C}$.

In addition, tests were carried out according to standards NT BUILD 443 [8] and ASTM C 1556 - 03 [9]. Three cylindrical samples of diameter $80 \mathrm{~mm}$ and a height of $50 \mathrm{~mm}$ were insulated at all of their surfaces, except the top, which at the same time is the top surface of the pre-stressed concrete slabs HC-500, were covered with resin. The samples were soaked in limewater as much as possible and then stored in a closed container immersed in $16.5 \%$ $\mathrm{NaCl}$ solution for 5 weeks (fig. 2a).

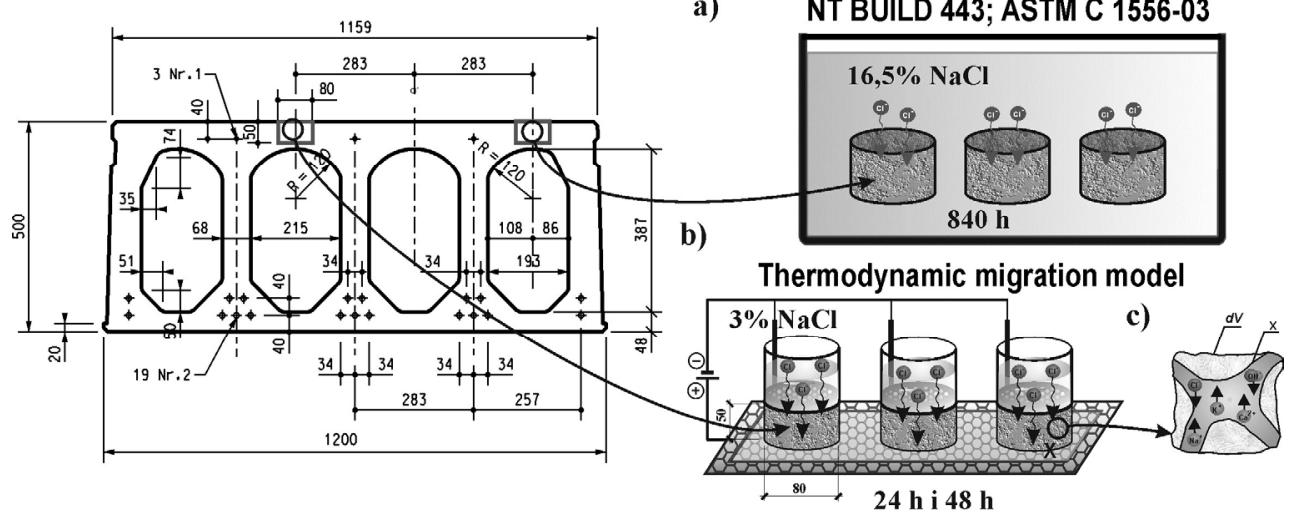

Fig. 2. Cross-section of HC500-19/R120 prefabricated, pre-stressed concrete slab: a) test stand according to standards NT BUILD 443 [8] and ASTM C 1556 - 03 [9], b) Schematic view of chloride migration model under external electric field, c) the process components in the representative volume element.

After completing both migration and diffusion, the samples were left in room conditions for 2 days. Then, the crumbled concrete samples were taken from each specimen with layers of thickness $\mathrm{g}=2 \mathrm{~mm}$ at 10 consecutive depths from the slab surface using the "Profile Grinding Kit" from Germann Instruments AS. The crushed concrete from the corresponding three analogous samples was combined and distilled water was added in a 1: 1 weight ratio. The thick solution was stirred every few hours for one day and then filtered through a medium filter. Leaching process was repeated twice. The model solutions were subjected to chemical analysis by determining according to the standard PN-ISO 9297 [12] by means of an argentometric titration according to Mohr concentration $\mathrm{c}^{1}\left[\mathrm{~g} / \mathrm{m}^{3}\right]$ chloride ions in the liquid - Table 1.

Since the crushed concrete was twice leached with water in a weight ratio $1: 1$, so the volume $V_{s}$ of the model liquid was estimated based on the water mass density $\gamma_{w}=1000$ $\mathrm{kg} / \mathrm{m}^{3}$ and the volume density $\rho^{l}$ of chloride ions in concrete was determined as follows [10].

$$
\rho^{l}=\frac{m^{l}}{V_{c}}=\frac{2 c^{l} \gamma_{c}}{\gamma_{w}},
$$

where $m^{l}$ is the chloride ions in volume $V_{s}, V_{c}$ is the volume of the concrete. During the accompanying tests, the volume weight of concrete $\gamma_{c}=2621 \mathrm{~kg} / \mathrm{m}^{3}$ were quantified. The calculations results for the mass density $\rho^{1}$ of chloride ions migrating and diffusing in the concrete samples are summarized in Table 1. Results for time instances 24 and 48 hours correspond to migration investigations, while results for time instance 840 hours correspond to migration investigation. 
Table 1. Concentration $c^{1}$ in the experimental solution and mass density $\rho^{1}$ in concrete - diffusion and migration of ions $\mathrm{Cl}^{-}$under the electric field

\begin{tabular}{|c|c|c|c|c|c|c|c|}
\hline \multirow[t]{2}{*}{$\begin{array}{l}\text { Depth } \\
\text { range } \\
{[\mathrm{mm}]}\end{array}$} & \multirow[t]{2}{*}{$\begin{array}{l}\text { Coordinate } \\
{[\mathrm{mm}]}\end{array}$} & \multicolumn{3}{|c|}{$\begin{array}{c}\mathrm{Cl}^{-} \text {Concentration in solution } \mathrm{c}^{1} \\
{\left[\mathrm{~g} / \mathrm{m}^{3}\right]}\end{array}$} & \multicolumn{3}{|c|}{$\begin{array}{c}\text { Density of mass } \mathrm{Cl}^{-} \\
\text {in concrete } \rho^{1} \\
{\left[\mathrm{~kg} / \mathrm{m}^{3}\right]}\end{array}$} \\
\hline & & $\mathrm{t}_{1}=24 \mathrm{~h}$ & $\mathrm{t}_{2}=48 \mathrm{~h}$ & $\mathrm{t}_{3}=840 \mathrm{~h}$ & $\mathrm{t}_{1}=24 \mathrm{~h}$ & $\mathrm{t}_{2}=48 \mathrm{~h}$ & $\mathrm{t}_{3}=840 \mathrm{~h}$ \\
\hline $0 \div 2$ & 1 & 306.60 & 577.6 & 592 & 1.61 & 3.03 & 3.10 \\
\hline $2 \div 4$ & 3 & 114.10 & 57.8 & 234 & 0.60 & 0.30 & 1.23 \\
\hline $4 \div 6$ & 5 & 40.30 & 29 & 48.7 & 0.21 & 0.15 & 0.26 \\
\hline $6 \div 8$ & 7 & 24.60 & 14.3 & 23.6 & 0.13 & 0.07 & 0.12 \\
\hline $8 \div 10$ & 9 & 18.60 & 14.1 & 15.53 & 0.10 & 0.07 & 0.08 \\
\hline $10 \div 12$ & 11 & 13.10 & 12.1 & 28.7 & 0.07 & 0.06 & 0.15 \\
\hline $12 \div 14$ & 13 & 16.00 & 15.4 & 23 & 0.08 & 0.08 & 0.12 \\
\hline $14 \div 16$ & 15 & 5.30 & 4.9 & 12.6 & 0.03 & 0.03 & 0.07 \\
\hline $16 \div 18$ & 17 & 1.80 & 8 & 16.3 & 0.01 & 0.04 & 0.09 \\
\hline
\end{tabular}

Based on the expression determining the diffusion coefficient of chloride ions $D^{l}=1 / Q-$ which is the reverse of the diffusion resistance of the entire tested concrete zone with the range $a$

$$
D^{1}=\frac{\bar{j}^{l}(a) a \Delta t}{\frac{z^{1} F U g}{R T h}\left[\bar{\rho}_{1} l_{1}+\bar{\rho}_{2}^{1}+\ldots+\bar{\rho}_{n}^{l}\right] \Delta t-B}, \quad B=\int_{0}^{a} Q_{x}\left[\rho^{l}(x, t+\Delta t)-\rho^{l}(x, t)\right] d x .
$$

In this expression, $\bar{j}^{1}(\mathrm{a})$ is the value of the mass flow of chloride ions passing through the plane situated at a distance $x=a, \bar{\rho}_{1}^{l}, \bar{\rho}_{2}^{l}, \mathrm{i} \bar{\rho}_{n}^{l}$ are the averaged in time $\Delta t$, mass densities of ion $\mathrm{Cl}^{-}$at midpoints of consecutive intervals $[0, \mathrm{~g}],[\mathrm{g}, 2 \mathrm{~g}], \ldots,[(\mathrm{n}-1) \mathrm{g}$, a]. The first component of the denominator defines the stationary part of the chloride ion flows, while the second component $\mathrm{B}-$ defines non-stationary part. In this expression, $z^{l}$ is the ion valence, $\mathrm{R}=8.317 \mathrm{~J} / \mathrm{mol} \cdot \mathrm{K}-$ universal gas constant, $\mathrm{F}=96487 \mathrm{C} / \mathrm{mol}$ - the Faraday constant, $\mathrm{U}-$ the voltage between the electrodes, $\mathrm{h}$ - the specimen height [10].

On the basis of measurements of mass density distribution $\rho^{1}$ of chloride ions migrating in concrete under the influence of the electric field, a reliable value of the diffusion coefficient was determined using the dependence (2). The results of calculations are summarized in table 2 .

Table 2. The list of calculated results for the diffusion coefficient of ions $\mathrm{Cl}^{-}$

\begin{tabular}{|c|c|c|c|c|c|c|c|}
\hline \multirow{3}{*}{ 今̃ } & \multirow{3}{*}{$\Xi$} & \multirow{3}{*}{$\begin{array}{l}D^{1} \\
=\cdot 10^{-12} \\
{\left[\mathrm{~m}^{2} / \mathrm{s}\right]}\end{array}$} & \multicolumn{5}{|c|}{$D^{1}{ }_{n s}=\cdot 10^{-12}\left[\mathrm{~m}^{2} / \mathrm{s}\right]$} \\
\hline & & & \multicolumn{5}{|c|}{ Non-stationary influence } \\
\hline & & & $10 \%$ & $20 \%$ & $30 \%$ & $40 \%$ & $50 \%$ \\
\hline \multirow[b]{2}{*}{ I } & 24 & 0.05 & 0.06 & 0.07 & 0.08 & 0.09 & 0.11 \\
\hline & 48 & 0.14 & 0.16 & 0.19 & 0.20 & 0.24 & 0.29 \\
\hline \multirow{2}{*}{ VIII } & 24 & 2.48 & 2.72 & 3.22 & 3.47 & 4.21 & 4.95 \\
\hline & 48 & 0.44 & 0.48 & 0.57 & 0.61 & 0.74 & 0.87 \\
\hline \multicolumn{2}{|c|}{$\overline{\mathrm{D}}^{1}$} & 0.72 & 0.79 & 0.94 & 1.01 & 1.22 & 1.44 \\
\hline
\end{tabular}


The obtained value of the diffusion coefficient $\bar{D}_{s}^{1}=0,72 \cdot 10^{-12} \mathrm{~m}^{2} / \mathrm{s}$, determined in the steady state in the concrete under consideration classifies it to the group of concretes with very low permeability to chlorides $[10,13,14]$.

Using the method of determining the diffusion coefficient described in the standards NT BUILD 443 [8] and ASTM C 1556 - 03 [9] on the basis of the diffusion coefficients set in Table 2, distribution of chloride mass density in concrete was calculated according to the known solution of the diffusion equation

$$
\rho_{c a l}^{1}(x, t)=\rho_{0}^{1}\left(1-e r f \frac{x}{2 \sqrt{D^{1} t}}\right), \quad D^{1}=D_{s}^{1}, \quad D^{1}=D_{n s}^{1}
$$

where $\rho_{0}^{1}$ means the concentration of chlorides on the edge, erf is Gauss error function, $t$ refers to time, $x$ stands for coordinate of the point and compared to distributions of chloride mass density $\rho^{1}(x, t)$ obtained empirically in diffusion studies. Using the least mean square error between the calculated values $\rho_{\text {cal }}^{1}(x, t)$ and determined experimentally $\rho^{1}(x, t)$ the value of the diffusion coefficient was determined $D^{1}{ }_{n s}=1,44 \cdot 10^{-12} \mathrm{~m}^{2} / \mathrm{s}$. In the tested concrete, the influence of the non-stationarity of the process during the operation of chlorides lasting 5 weeks $(840 \mathrm{~h})$ was $(\omega=0.5)$.

\section{Bayesian inverse estimation of diffusion coefficients of chlorides}

\subsection{Inverse procedure}

The paper presents Bayesian Inverse approach applied to estimate value of diffusion coefficient of chloride in the precast concrete based on the local values of chloride concentrations. In this approach all unknown estimated parameters are treated as random variables and their distribution is determined in this methodology. Having distribution of unknown parameters their expected values can be easily obtained together with error bounds.

In the Bayesian approach the posterior distribution function of the unknown parameters is written as a conditional distribution using Bayes theorem [15]:

$$
\pi\left(\mathbf{P} \mid \boldsymbol{\rho}_{m}^{1}\right)=\frac{\pi\left(\boldsymbol{\rho}_{m}^{1} \mid \mathbf{P}\right) \pi(\mathbf{P})}{\pi\left(\boldsymbol{\rho}_{m}^{1}\right)}
$$

where $\pi\left(\mathbf{P} \mid \mathbf{\rho}_{m}^{1}\right)$ is the posteriori distribution of the unknown parameters, $\pi\left(\boldsymbol{\rho}_{m}^{1} \mid \mathbf{P}\right)$ refers to likelihood distribution, $\pi(\boldsymbol{P})$ stands for the priori distribution of the parameters and $\pi\left(\boldsymbol{\rho}_{m}^{1}\right)$ is a marginal distribution of the measurements, which may be treated as a normalisation constant [15]. $\boldsymbol{\rho}_{m}^{1}$ is the vector of the measured chloride concentration at given sampling points after given time. In order to develop the likelihood distribution it is assumed that [15]:

- consecutive measurements are independent,

- measurement errors are additive, Gaussian and with zero mean.

Hence, the likelihood distribution takes the shape of multivariate Gaussian distribution:

$$
\pi\left(\boldsymbol{\rho}_{m}^{1} \mid \mathbf{P}\right) \propto \exp \left[\left(\boldsymbol{\rho}_{m}^{1}-\boldsymbol{\rho}_{c}^{1}(\mathbf{P})\right)^{T} \boldsymbol{\sigma}_{\rho}^{-2}\left(\boldsymbol{\rho}_{m}^{1}-\boldsymbol{\rho}_{c}^{1}(\mathbf{P})\right)\right]
$$


It was assumed that no prior information except the ranges of unknown parameters is available on the value of estimated diffusion coefficient, hence the prior distribution was:

$$
\pi(\boldsymbol{P})=\left\{\begin{array}{cc}
\frac{1}{\prod_{i=1}^{M}\left(P_{i, u}-P_{i, l}\right)} & \boldsymbol{P} \in\left[P_{1, l} ; P_{1, u}\right] \times \ldots \times\left[P_{M, l} ; P_{M, u}\right] \\
0 & \text { elsewhere }
\end{array}\right.
$$

The posteriori distribution of the unknown diffusion coefficient cannot be evaluated analytically, only samples of an approximate distribution can be generated. In this paper the Metropolis-Hastings algorithm was used to generate the Markov Chains which sampled the unknown posteriori distribution [15]. The algorithm is as follows:

1. Draw a candidate point $\widetilde{\mathbf{P}}$ from a proposal distribution $\pi\left(\widetilde{\mathbf{P}}, \mathbf{P}^{i-1}\right)$.

2. Calculate the acceptance factor:

$$
\gamma=\min \left\{1, \frac{\pi\left(\widetilde{\mathbf{P}} \mid \mathbf{\rho}_{m}^{1}\right) \pi\left(\mathbf{P}^{i-1}, \widetilde{\mathbf{P}}\right)}{\pi\left(\mathbf{P}^{i-1} \mid \mathbf{\rho}_{m}^{1}\right) \pi\left(\widetilde{\mathbf{P}}, \mathbf{P}^{i-1}\right)}\right\}
$$

3. Draw a random number $\mathrm{R}$ that is uniformly distributed in $[0 ; 1]$.

4. Accept the candidate point if $R<\gamma$ and set $\boldsymbol{P}^{i}=\widetilde{\boldsymbol{P}}$. Otherwise, set $\boldsymbol{P}^{i}=\boldsymbol{P}^{i-1}$, where $\pi\left(\boldsymbol{P}^{i-1}, \widetilde{\boldsymbol{P}}\right)$ and $\pi\left(\widetilde{\boldsymbol{P}}, \boldsymbol{P}^{i-1}\right)$ are proposal distributions of achieving point $\boldsymbol{P}^{i-1}$ from point $\widetilde{\boldsymbol{P}}$ and in the opposite direction, respectively. In this work, uniform random-walk proposal was used for each parameter. Therefore, the acceptance factor formula simplifies to the expression [21]:

$$
\gamma=\min \left\{1, \frac{\pi\left(\widetilde{\mathbf{P}} \mid \boldsymbol{\rho}_{m}^{1}\right)}{\pi\left(\mathbf{P}^{i-1} \mid \boldsymbol{\rho}_{m}^{1}\right)}\right\}
$$

Usually, the starting point of the Markov chains can be relatively far from the solution. Therefore, some number of the initial states of the Markov Chains have to be discarded until the chains have not reached equilibrium (this is so called burn-in period).

\subsection{Direct problem solution}

The problem of chloride transport in the concrete can be relatively well described by the diffusion equation. Moreover, the experimental setup was designed in such a way that the problem can be treated as an unsteady and one dimensional diffusion problem:

$$
\frac{\partial \rho^{1}}{\partial \tau}=\frac{\partial}{\partial x}\left[D^{1}\left(\rho^{1}\right) \frac{\partial \rho^{1}}{\partial x}\right]
$$

At one end of the analysed concrete block there can be assumed a constant value of the chloride concentration while at the other end value equal to zero can be prescribed. At the initial state concentration of chlorides in the concrete block was assumed equal to zero. These assumptions give following boundary and initial conditions:

$$
\begin{aligned}
& \rho^{1}(0, \tau)=\rho_{e q}^{1}(\tau) \\
& \rho^{1}(0, \tau)=0 \\
& \rho^{1}(x, 0)=0
\end{aligned}
$$


where $\rho^{1}$ is the concentration of chloride, $\tau$ stands for time, $x$ is the spatial variable and $l$ is the thickness of the considered block. $D^{1}$ designates the diffusion or migration coefficient, $\rho^{1}{ }_{e q}(\tau)$ is the known chloride concentration value at the boundary adjacent to the water chloride solution. The above Initial Boundary Value (IBV) problem was solved using Global Radial Basis Function Collocation method which is very fast and robust method of solving IBV problems [16].

\subsection{Results of estimation}

In Figure 2 and 4 an unknown distribution of chloride migration coefficient is presented, which were obtained using concentration measured after 24 and 48 hours appropriately. It can be seen that the distributions are close to the Gaussian distributions. The expected values of migration coefficient obtained for 24 hours measurements differs from the expected value of the migration coefficient obtained for 48 hours measurements. This reveals influence of the time on the Chlorides transport process in the concrete. The standard deviation which can be treated as an estimate of the error of determined quantity, is equal to around $20 \%$ of the expected value for the estimate based on 24 hours measurements. While the standard deviation for estimate based on the 48 hours measurements equals to about $10 \%$ of the expected value. This is quite high and it means that uncertainty of the estimated quantity is significant. In figures 3 and 5 computed and measured profiles of the Chloride concentrations in the investigated samples are presented. It can be seen that that the model described by equations (9) and (10) reasonably well reproduce experimental data.

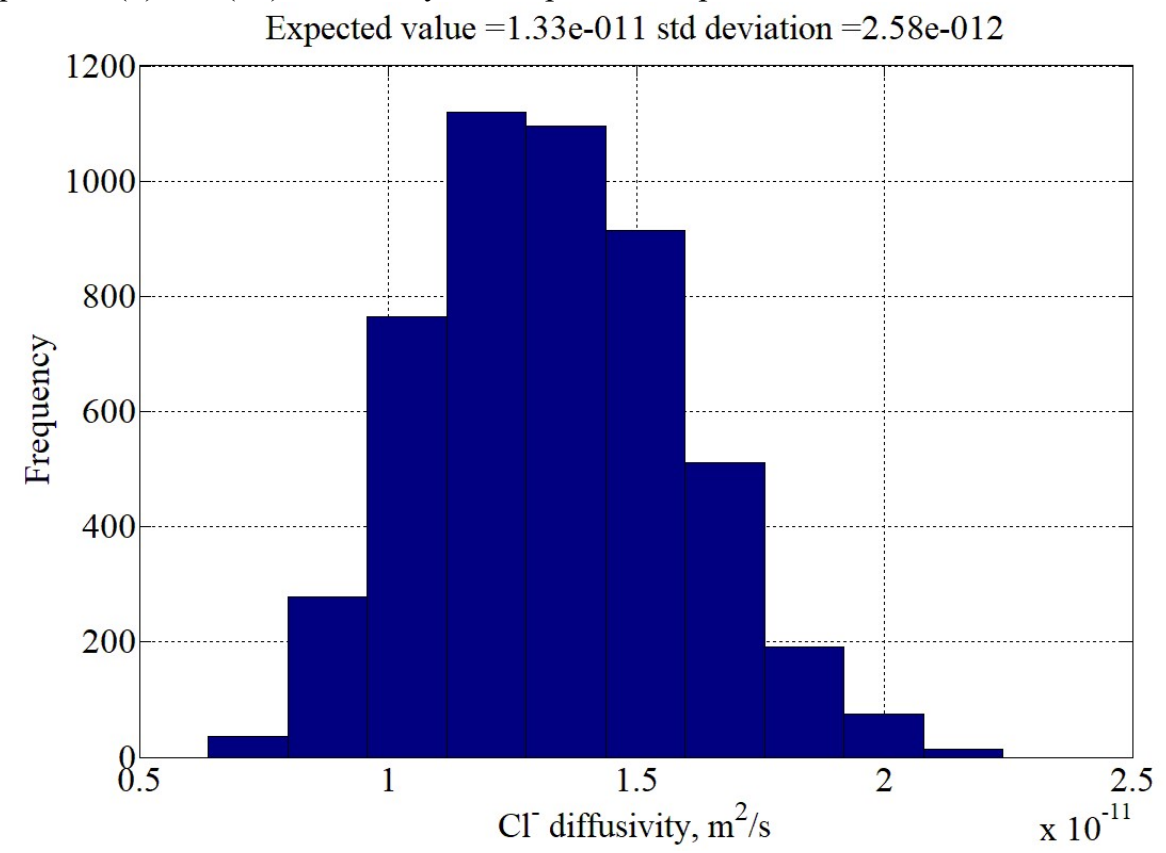

Fig. 2. Estimated distribution of the diffusion coefficient of chlorides inside the concrete sample based on the Chloride concentration measurements carried out after 24 hours of experiment.

In Figure 3 measured and calculated profile of chlorides along the sample height is shown. Reasonably good fitting of the measured values was obtained. 


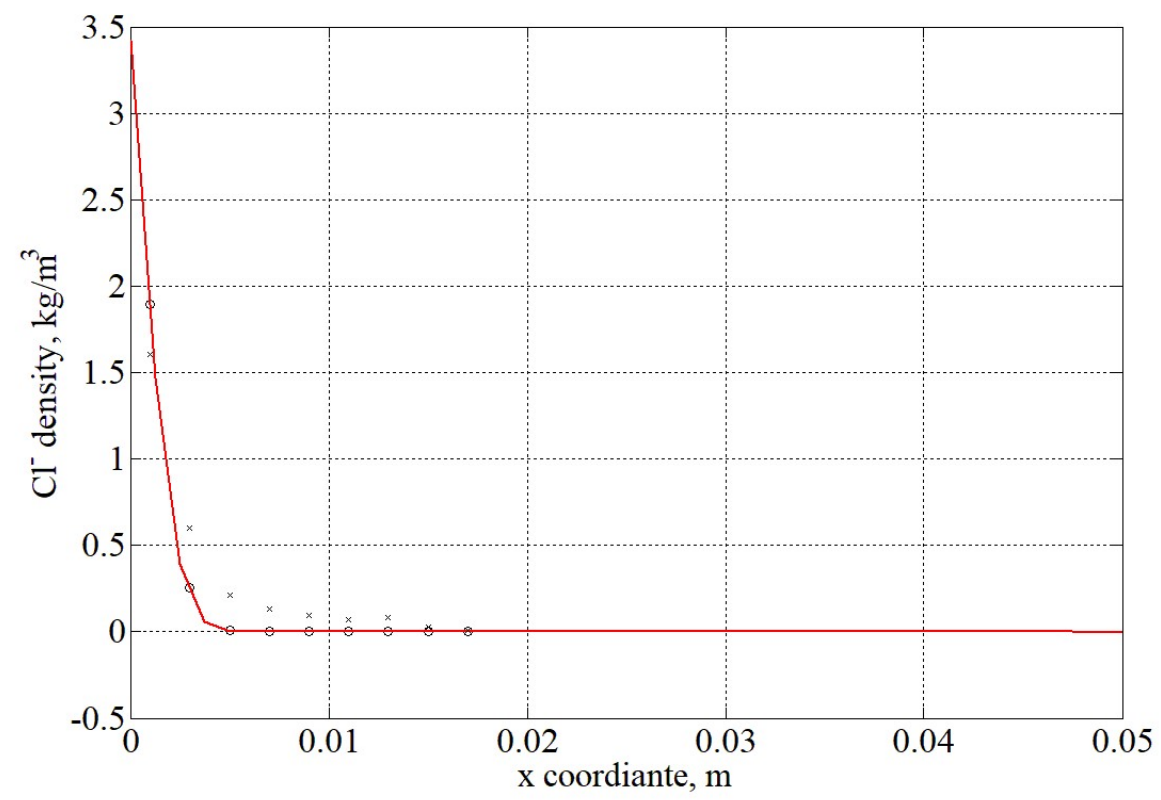

Fig. 3. Comparison of the profile of measured and computed chloride concentration along the height of the sample for the Chloride concentration measurements carried out after 24 hours of experiment.

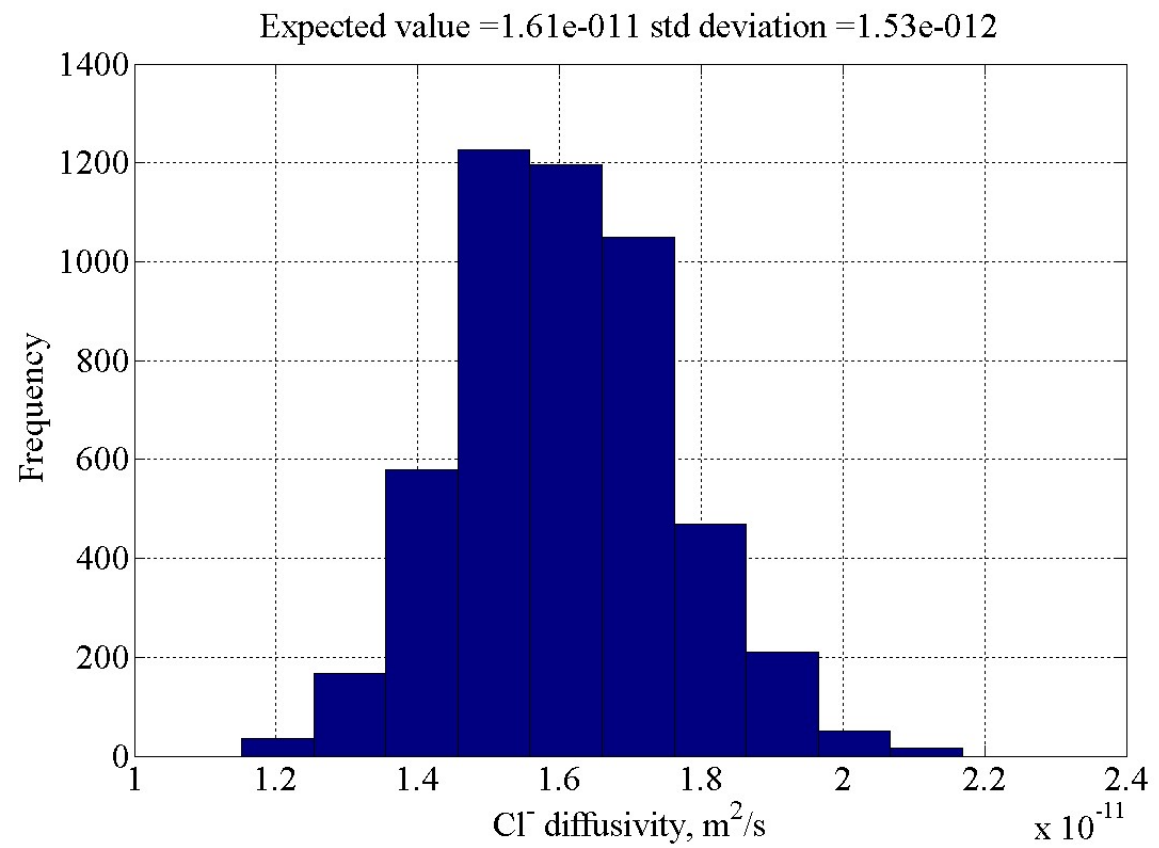

Fig. 4. Estimated distribution of the diffusion coefficient of chlorides inside the concrete sample based on the Chloride concentration measurements carried out after 48 hours of experiment.

In Figure 3 measured and calculated profile of chlorides along the sample height is shown. Reasonably good fitting of the measured values was obtained. 


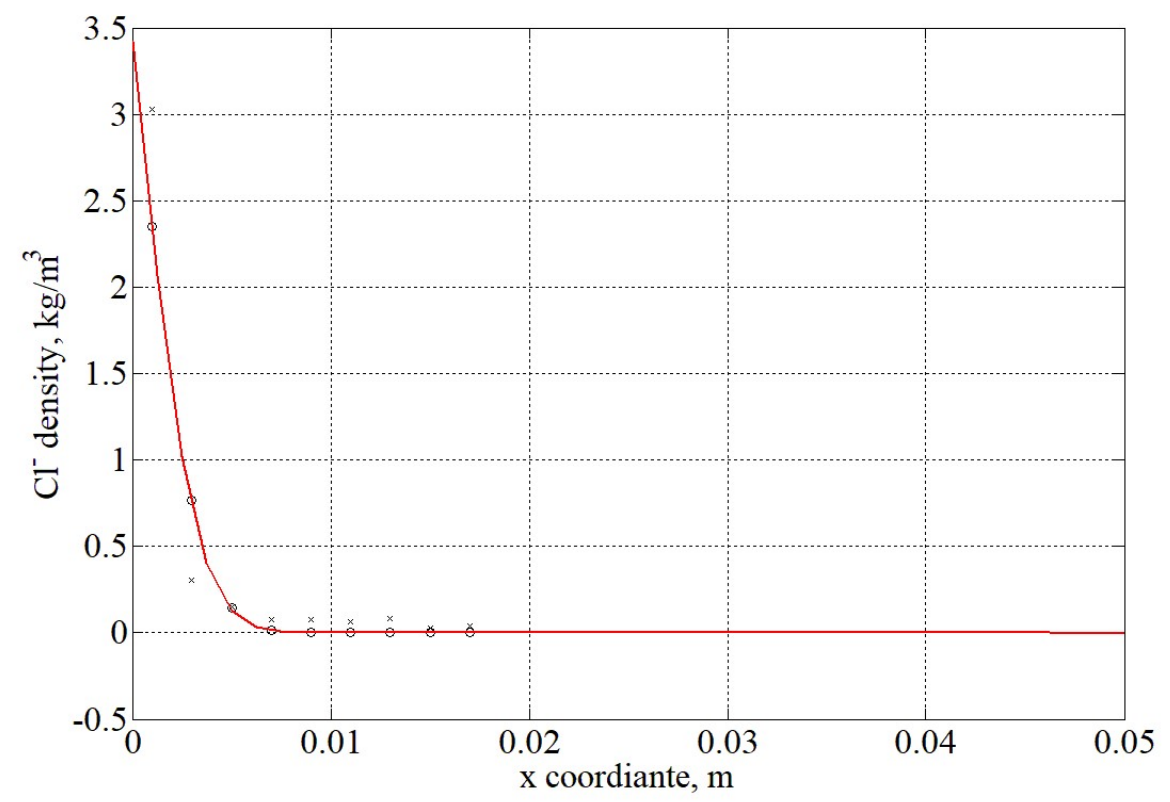

Fig. 5. Comparison of the profile of measured and computed chloride concentration along the height of the sample for the Chloride concentration measurements carried out after 48 hours of experiment.

\section{Summary}

On the basis of measurements of mass density distribution of chloride ions migrating in concrete under the influence of the electric field, a reliable value of the diffusion coefficient was determined $\bar{D}_{s}^{1}=0,72 \cdot 10^{-12} \mathrm{~m}^{2} / \mathrm{s}$. Using the method of determining the diffusion coefficient described in the standards NT BUILD 443 [8] and ASTM C $1556-03$ [9] on the basis of the least mean square error between the calculated values and determined experimentally the value of the diffusion coefficient was determined $D_{n s}^{1}=1.44 \cdot 10^{-12} \mathrm{~m}^{2} / \mathrm{s}$.

The paper presents also application of Bayesian methodology to estimate diffusion coefficient of chlorides in the precast concrete. The developed methodology successfully estimated unknown value and its distribution. The expected value of the diffusion coefficient was $D^{1}{ }_{m i g}=1.33 \cdot 10^{-11} \mathrm{~m}^{2} / \mathrm{s}$ for 24 hours measurements and $D^{1}{ }_{m i g}=1.61 \cdot 10^{-11} \mathrm{~m}^{2} / \mathrm{s}$ for 48 hours measurements. It appeared that the estimation error is between 10 and $20 \%$ of the original value of the coefficient.

The value of the migration coefficient determined using the inverse method with application of Bayesian methodology is around 10 times greater than the value determined both by the thermodynamic migration model and according to standards NT BUILD 443 [8] and ASTM C 1556 - 03 [9]. This agrees with the values of diffusion and migration coefficients published in the literature of the subject $[17, .18]$. 


\section{References}

1. A. Ajdukiewicz, J. Mames, Konstrukcje z betonu sprężonego. Polski Cement ; Kraków (2004)

2. Wytyczne projektowania stropów z płyt sprężonych „HC”. Poradnik dla projektantów. „Steelco" Grzegorz Troszczyński (na zamówienie firmy: FABUD Wytwórni Konstrukcji Betonowych S.A, Siemianowice Śląskie (2013)

3. PN-EN 1992-1-1 Eurokod 2 - Design of concrete structures - Part 1-1: General rules and rules for buildings.

4. PN-EN 206-1: 2003 Beton. Część 1: Wymagania, właściwości produkcja i zgodność.

5. BS 8110: Part 1: 1997 (Amendment No. 1: 1998) Structural use of concrete. British Standard Institution, September (1998)

6. ACI 318M-02/318RM02 (Metric Version) Building code requirementts for structural concrete (ACI 318M-02) and commentary (ACI 318RM-02) American Concrete Institute, Farmington Hills. (2002)

7. Czarnecki L., Woyciechowski P. Ocena trwałości konstrukcji z betonu w warunkach zagrożenia karbonatyzacją i korozją chlorkową. XIII Konferencja NaukowoTechniczna, Warsztat Pracy Rzeczoznawcy Budowlanego. 102-124 (2014)

8. NT BUILD443. Concrete, hardened: Accelerated chloride penetration. Approved 1995-11.

9. ASTM C 1556 - 03. Standard test method for determining the apparent chloride diffusion coefficient of cementitious mixtures by bulk diffusion. American Society for Testing and Material, Philadelphia 2003.

10. Szweda Z., Zybura A.:Theoretical model and experimental tests on chloride diffusion and migration processes in concrete - Procedia Engineering. Vol. 57, p. 1121-1130, (2013)

11. https://roosevelta81.pl/stadion/jak-to-jest-zrobione/konstrukcja/poziom-0/

12. PN-ISO 9297: Determination of chlorides. Titration method with silver nitrate in the presence of chromate as indicator (Mohr Methode).

13. Szweda Z.: Badania oporu wnikania chlorków do betonu na cementach portlandzkim zwykłym i niskoalkalicznym. Ochrona przed korozją,148-153, (2016).

14. Szweda Z., Ponikiewski T., Katzer J.: A study on replacement of sand by granulated ISP slag in SCC as a factor formatting its durability against chloride ions. Journal of Cleaner Production. 156:569-576, (2017).

15. Kaipio J. and Somersalo E.,Statistical and computational inverse problems, SpringerVerlag New York, (2004).

16. Bulinski Z., Orlande H.R.B., Estimation of the non-linear diffusion coefficient with Marcov Chain Monte Carlo method based on the integral information, International Journal of Numerical Methods for Heat \& Fluid Flow, Vol. 27 Issue: 3, pp.639-659, (2017).

17. Andrade C., Sanjuán M. A., Recuero A., Río O.: Calculation of chloride diffu-sivity in concrete from migration experiments, in non steady-state conditions. Cement and Concrete Research; Vol. 24, no 7, pp. 1214-1228, (1994)

18. Delagrave A., Marchand J., Samson E.: Prediction of diffusion coefficients in cementbased materials on the basis of migration experiments. Cement and Concrete Research; Vol. 26, No. 20, pp. 1831-1842, USA, (1996) 